\title{
Huawei’s Intellectual Property Strategy and Its Enlightenment
}

\author{
Juan Zhao \\ School of Government Management \\ Beijing Normal University \\ Beijing, China
}

\begin{abstract}
This paper analyzes Huawei's intellectual property strategy, including integrating intellectual property strategy into the company's overall strategy, increasing $R \& D$ investment year by year and attaching importance to independent research and development, attaching importance to patented technology, carrying out intellectual property training and respecting the intellectual property rights of others. On the basis of this understanding, this paper analyzes the enlightenment: ideologically establish the strategic consciousness of intellectual property rights, enterprises should establish intellectual property management system, build full participation in intellectual property rights and protect and strengthen the effective operation of patents.
\end{abstract}

Keywords-Huawei; intellectual property; strategy; patent

\section{INTRODUCTION}

Huawei is one of the outstanding national enterprises in China. In recent years, it has made outstanding scientific exploration in the development of high-tech industry, which has promoted the development of science and technology in China and the world. In the process of the development of enterprise science and technology, an important link that can't be ignored is the attention and utilization of intellectual property rights from beginning to end. Huawei was founded in 1987, just as China's Patent Law was promulgated. At the beginning of its establishment, the company established an intellectual property system within the enterprise that respects knowledge, attaches importance to science, and promotes technological progress. Based on this system, a complete industrial chain of technology development, transformation and utilization has been established, and achievements have been made that have attracted worldwide attention. Huawei has the world's largest number of patents filed in 2018, in addition to its forward-looking vision of applying for blockchain-related patents as early as 2016 . Therefore, it is necessary to make an in-depth analysis of Huawei's intellectual property strategy, empirically explore its operation, and get the corresponding inspiration.

\section{Huawei Intellectual Property Strategy}

\section{A. Integrating Intellectual Property Strategy into the}

Company's Overall Strategy

Huawei set up its intellectual property department in 1995, but it has not received much attention. After China joined the WTO in 2001, Huawei realized the importance of intellectual property rights, but really began to pay attention to it after the Cisco case in 2003. The Cisco case has made Huawei deeply aware of the importance of intellectual property rights to the international development of enterprises. Intellectual property rights are an important link for enterprises to open up international markets and participate in world economic exchanges and cooperation. As a result, the systematic and purposeful implementation of the intellectual property strategy has begun. Huawei intellectual property strategy is an important part of the company's overall development strategy, it should be forward-looking, the overall situation to serve the overall development of the company. The status of the intellectual property Department is as important as the R\&D Department, the production Department and the Marketing Department, and the top leader of the sales line of the production line is responsible for the company's major intellectual property decisions.

\section{B. Increasing $R \& D$ Investment Year by Year and Attaching Importance to Independent $R \& D$}

Huawei is soberly aware that independent $R \& D$ is the cornerstone of high-tech enterprises, and pays attention to improving the core technology of endogenous growth, and $R \& D$ investment is one of the important indicators to reflect the degree of importance enterprises attach to scientific and technological innovation. Therefore, Huawei insists on spending more than $10 \%$ of its annual sales revenue on product research and development, and on basic technology, core technology, and cutting-edge technology. If necessary, it will adjust and increase the proportion of R\&D investment according to business development or strategic objectives. At its peak, R\&D investment accounted for $15.1 \%$ of sales in 2015 (See "Fig. 1"). As can be seen from "Fig. 1", Huawei's investment in R\&D costs has basically maintained an increasing trend, which has also provided a solid material basis for scientific research and development. And facts have 
and the formation of a benign innovation system (See "Fig. 2"). also proved that the high investment in $R \& D$ has brought high returns to Huawei, promoted the enhancement of its independent R\&D strength, the steady growth of net profit,

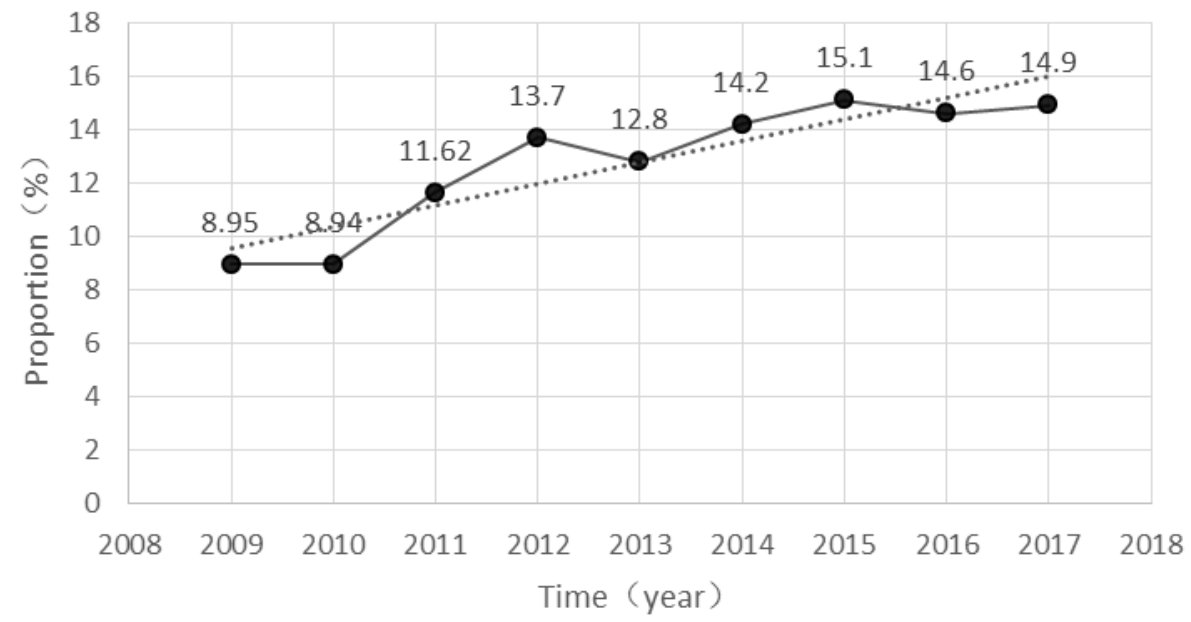

Fig. 1. 2009-2017 Huawei R\&D investment to sales revenue ratio. (Data source: collated according to the number of Huawei annual reports over the years.)

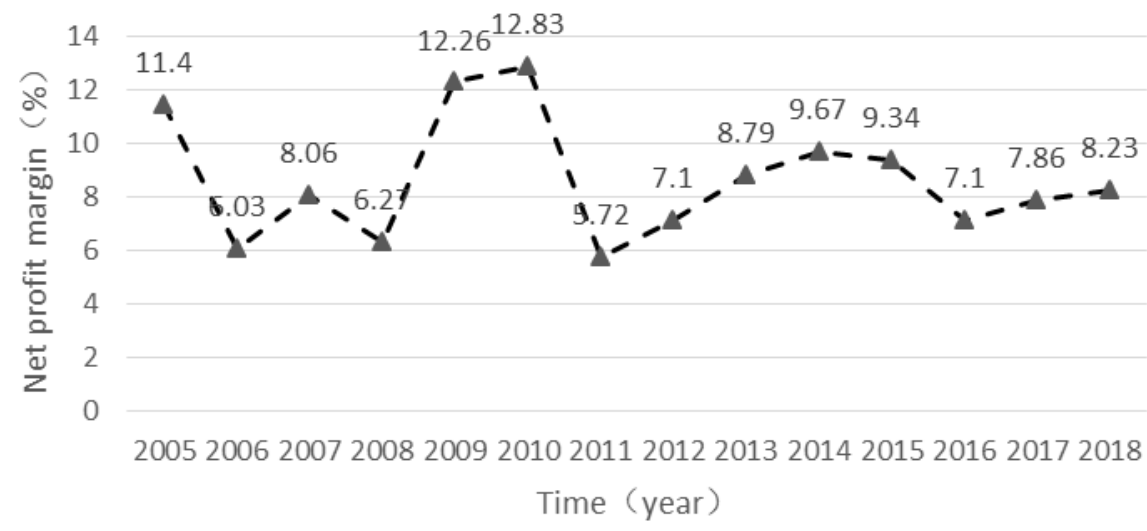

Fig. 2. 2005-2018 Huawei net profit margin. (Data source: collated according to the number of Huawei annual reports over the years)

\section{Attaching Importance to Patented Technology}

Huawei is rich in intellectual property reserves and accumulates core intellectual property rights, with particular emphasis on patent technology innovation. With more than 30 years of unremitting efforts, Huawei has developed from an enterprise with "no independent innovation products" to one that is now in the forefront of patent applications in the world and showing a steady growth trend. And most of these patents belong to invention patents with high scientific and technological content. Thus, the sufficient number of patents and the necessary patent quality play a vital role in Huawei's national and global high-tech development, and promote Huawei to become a leader in the communications industry. In addition to attaching importance to patented technology, Huawei is also actively implementing the patent map program. After the Cisco case, Huawei was deeply aware of the importance of intellectual property rights to enterprises in opening up international markets, especially the importance of patent strategy. Patent strategy is an indispensable way for enterprises to obtain sustainable development, an important guarantee for the realization of technological innovation, and an effective means for enterprises to enhance their vitality. An important way for Huawei to implement its patent strategy is to implement the patent map plan. Patent map is an important part of Huawei patent strategy, is Huawei intellectual property combat map. According to the development needs of the company, Huawei analyzes the patent technology held by competitors in the industry, knows its position in the whole industry, and then takes corresponding measures. In addition, the patent map program is also an important means for Huawei to explore overseas markets. In view of the fact that many direct investment in development without patent technology analysis has caused the waste of technological resources to be ineffective instead of achieving the desired goal of technological development, before Huawei opened up a certain country or regional market, Through various professionals to conduct systematic 


\section{B. Enterprises Should Establish Intellectual Property Management System}

Perfecting intellectual property management system is not only the starting point of the implementation of intellectual property strategy, but also the basic work of the implementation of intellectual property strategy, which is closely related to the intellectual property strategy. The successful practical experience of Huawei in implementing its intellectual property strategy is to establish a corresponding intellectual property management department according to its own business status and technical strength. In addition, the intellectual property management department is regarded as an important part of enterprise management, but does not take the old way of emphasizing operation and neglecting scientific research in the ordinary enterprise development strategy. First of all, the intellectual property management department should play an important role in the whole management system of the enterprise, and should jointly form the core of the strategic decision-making of enterprise development in the direct productive department. Intellectual property management plays an important role in ensuring the implementation of intellectual property strategy. Second, the intellectual property management department should be fully responsible for the management of intellectual property rights within the enterprise, fully implement the implementation of the intellectual property system of the enterprise, and organize specific intellectual property work. Such as the collection of intellectual property related information, do a good job in market research, patent application and intellectual property related measures system and so on. Finally, the status of intellectual property management departments is important, but does not mean that the form of the department is immutable, but that its setting can be in a flexible form. Corresponding adjustments can be made according to the size, nature or development strategy of the enterprise, but the ultimate goal is to promote the development of the enterprise on an equal footing with other departments.

\section{A. Establishing the Strategic Consciousness of Intellectual Property Rights Ideologically}

Knowledge is the core force to enhance the ability of national innovation, the competition between countries in the future is bound to be the competition of scientific and technological strength, knowledge has been the key variable to promote economic endogenous growth. The truth is also applicable to enterprises. The innovative development and everlasting development of enterprises must constantly innovate knowledge and enhance science and technology, and these must first be set up ideologically, and scientific and technological innovation should be carried out under the guidance of this consciousness. Protect their own intellectual property rights and respect and make use of the intellectual property rights of others. Huawei's development history can be seen that every major historical period of its development has a clear intellectual property strategy, and each period of intellectual property strategy has been fully implemented at multiple levels. Therefore, in order to make the intellectual property strategy play its due role in enterprises, the most important task is to unify the understanding and strengthen the strategic consciousness of intellectual property rights.

\section{Construction of Intellectual Property Rights with Full Participation}

The full participation of the enterprise intellectual property strategy requires a number of departments to participate in the intellectual property mining, formation and management. Strengthen the intellectual property rights training for all staff, let employees establish the awareness of knowledge property rights protection, start from their own, constantly develop technological innovation, and promote technology dissemination and commercial transformation. At the same time, we should also establish a sense of respect for other people's intellectual property rights, do not infringe, and make rational use of them in accordance with the. Enterprises should also improve the system related to intellectual property rights, require all staff to devote themselves to the protection of intellectual property rights and risk aversion, and constantly strengthen the introduction of intellectual property professionals and the training of internal intellectual property talents, so as to form a benign mechanism for the cultivation and utilization of talents. 
D. Protecting and Strengthening the Effective Operation of Patents

Through the operation of intellectual property rights, enterprises can not only effectively protect their own technical assets, prevent or reduce infringement losses, but also open up new innovative development paths, seek new economic growth points, and realize the virtuous circle of enterprise development. Therefore, enterprise technology research and development should not only focus on the protection of intellectual property rights, but also learn and strengthen the connection between intellectual property rights and the production and operation of enterprises, the future development trend of enterprises, and the international development channels of enterprises. Make intellectual property become the core of the operation of the enterprise. The core of intellectual property operation is patent operation. Patent operation is the booster of enterprise progress and development, and it is the core competitiveness of enterprises. It is necessary to do a good job in patent layout, strengthen the introduction and training of R\&D personnel, and realize the effective use of patents by means of joint innovation, cross-licensing patents, patent transactions and so on.

\section{CONCLUSION}

Huawei's three decades of steady growth process and farsighted intellectual property strategy are worthy of learning and reference from domestic and foreign enterprises, especially high-tech enterprises. Its success can't be separated from the correct operation of enterprises, but also from Huawei's intellectual property strategy to keep pace with the times.

\section{REFERENCES}

[1] Wang Chunbo. A Brief Analysis of the Intellectual Property Rights of Huawei Technology Company Development and strategy. Legality Vision,2017,04:225-226.

[2] Guo Yusa. Analysis and Enlightenment of Huawei v. Samsung Patent Infringement Case. China Invention \& Patent, 2016,12:63-69.

[3] Wang Peilin. A Rational Analysis of Huawei's Knowledge Innovation Process. Science \& Technology Progress and Policy,2010,09:120-122.

[4] Ding Jianxin. Huawei's Open Innovation and Intellectual Property Values. China Invention \& Patent,2010,04:87-88.

[5] Liu Rong.The Development Course of Huawei Sustainable Supply Chain and Its Enlightenment. Monthly Journal of Finance and Accounting,2019,17:143-149. 